Arq. Bras. Med. Vet. Zootec., v.56, n.6, p.750-756, 2004

\title{
Silagens de girassol e de milho em dietas de vacas leiteiras: produção e composição do leite
}

\author{
[Sunflower silage and corn silage in lactating cow diets: milk production and composition] \\ B.O. Silva ${ }^{1}$, L.A. Leite ${ }^{1}$, M.I.C. Ferreira ${ }^{1}$, L.M. Fonseca ${ }^{2}$, R.B. Reis ${ }^{2} *$ \\ ${ }^{1}$ Estudante de Pos-graduação - Escola de Veterinária da UFMG \\ ${ }^{2}$ Escola de Veterinária da UFMG \\ Caixa Postal 567 \\ 30123-970 - Belo Horizonte, MG
}

\begin{abstract}
RESUMO
Avaliaram-se a produção e a composição do leite de vacas alimentadas com dietas contendo diferentes proporções de silagem de girassol, em substituição à silagem de milho na dieta, e caroço de algodão como substituto parcial do concentrado. Foram utilizadas cinco vacas holandesas com $25 \mathrm{~kg}$ leite/dia, distribuídas em um delineamento em quadrado latino $5 \times 5$. Os períodos foram de 21 dias e os tratamentos foram as dietas compostas por: $100 \%$ de silagem de girassol e concentrado (100SG), $66 \%$ de silagem de girassol e $34 \%$ de silagem de milho e concentrado (66SG), 34\% de silagem de girassol mais $66 \%$ de silagem de milho e concentrado (34SG), $100 \%$ de silagem de milho e concentrado (100SM) e $100 \%$ de silagem de milho mais caroço de algodão (16,5\% da matéria seca) e concentrado (16,5CA). As produções de leite, proteína e extrato seco total foram inferiores no tratamento $100 \mathrm{SG}$ em relação ao $100 \mathrm{SM}$ $(\mathrm{P}<0,05)$. A substituição parcial de silagem de milho por silagem de girassol não afetou as produções de leite, gordura ou proteína. A substituição parcial de concentrados por caroço de algodão não afetou as características estudadas.
\end{abstract}

Palavras-chave: gado leiteiro, girassol, silagem

\begin{abstract}
Milk production and composition of Holstein cows fed diets in which sunflower silage replaced corn silage as the forage component were studied. Five Holstein cows with $25 \mathrm{~kg}$ milk/day, 60 to $82 \mathrm{DIM}$, were arranged in a $5 \times 5$ Latin Square design. Periods were 21 days and treatments were: 100\% sunflower silage plus concentrate (100SG); $66 \%$ sunflower silage, 34\% corn silage plus concentrate (66SG); $34 \%$ sunflower silage, $66 \%$ corn silage plus concentrate (34SG); 100\% corn silage plus concentrate (100SM); or 100\% corn silage plus whole cottonseed (16.5\% of dry matter) and concentrate (16.5CA). Milk yield, milk protein yield, and total milk solids yield were lower for 100SG compared to 100SM $(P<0.05)$. Partial replacement of corn silage with sunflower silage did not affect milk, fat and protein yield. Partial replacement of concentrates with whole cottonseed did not affect any of the studied variables.
\end{abstract}

Keywords: dairy cows, silage, sunflower

Recebido para publicação em 10 de dezembro de 2003

Recebido para publicação, após modificações, em 8 de agosto de 2004

*Autor para correspondência (corresponding author)

E mail: rbreis@vet.ufmg.br 


\section{INTRODUÇÃO}

A busca por alternativas para alimentação de vacas leiteiras e o estudo comparativo das variáveis produtivas relacionadas a alimentos que possam substituir os tradicionais deve ser uma constante na pesquisa brasileira.

McGuffey e Schingoethe (1980) e Thomas et al. (1982) relataram produções similares de leite corrigido para $4 \%$ de gordura (LCG $4 \%$ ) em vacas alimentadas com silagem de milho ou com silagem de girassol. Valdez et al. (1988), ao trabalharem com silagem de milho, silagem de girassol e silagem de milho com girassol (cultivadas e ensiladas simultaneamente), observaram maior produção de leite para as vacas alimentadas com esta última em relação às vacas alimentadas com silagem de milho.

DePeters et al. (1985) forneceram diferentes quantidades de caroço de algodão em substituição ao concentrado para vacas em lactação e concluíram que a produção de leite não foi afetada pela inclusão do caroço de algodão nas dietas, mas a produção de LCG 4\% foi aumentada.

A silagem de girassol e o caroço de algodão são alimentos ricos em lipídeos (Thomas et al., 1982; Arieli, 1998) e seus efeitos em dietas ricas em lipídeos para ruminantes têm sido inconsistentes (Yang et al., 1978). Alterações nos teores de gordura do leite com a adição de lipídeos na dieta de vacas já foram relatadas (Steele e Moore, 1968; Pennington e Davis, 1975), e são atribuídas ao método de administração e ao tipo e quantidade de lipídios fornecidos (Pennington e Davis, 1975; Astrup et al., 1976).

McGuffey e Schingoethe (1980) relataram que o extrato etéreo na silagem de girassol é três a quatro vezes maior que o da silagem de milho. Tomich et al. (2003), ao trabalharem com silagens de 13 cultivares de girassol, observoaram conteúdo médio de $13,7 \%$ de extrato etéreo nas amostras. O óleo da silagem de girassol é bastante rico em ácidos graxos insaturados. Nele o ácido linoléico (C18:2) encontra-se em maior quantidade $(69,4 \%)$, seguido pelo ácido oléico (C18:1; 21,2\%) (Kelly et al., 1998).

O caroço de algodão apresenta bom valor nutricional para vacas de média e alta produção leiteira (Chandler, 1992). Segundo o National... (2001), o conteúdo de lipídios é alto, representando em média $20 \%$ da matéria seca. Isso se reflete no alto conteúdo energético, cerca de 2,23Mcal de energia líquida para a lactação (ELL). O óleo é rico em ácidos graxos insaturados como o linoléico $(62 \%)$ e o oléico (15\%) (Smith et al., 1981).

O objetivo deste trabalho foi avaliar a produção e a composição do leite de vacas alimentadas com silagem de girassol em substituição total ou parcial à silagem de milho e a substituição parcial do concentrado na dieta pelo caroço de algodão.

\section{MATERIAL E MÉTODOS}

Foram utilizadas cinco vacas da raça Holandesa, pluríparas, entre 60 e 82 dias em lactação, com média de $25 \mathrm{~kg}$ de leite, alojadas individualmente em instalações tipo tie stall. Os animais foram distribuídos aleatoriamente nos tratamentos em delineamento de quadrado latino $(5 \times 5)$. Cinco períodos experimentais foram avaliados com duração de 21 dias cada, sendo 14 dias para adaptação e sete para coleta de dados.

Os tratamentos consistiram da substituição parcial ou total da silagem de milho pela silagem de girassol e substituição parcial do concentrado da dieta pelo caroço de algodão em dieta de $100 \%$ silagem de milho, a saber: $100 \%$ de silagem de girassol mais concentrado (100SG), $66 \%$ de silagem de girassol e $34 \%$ de silagem de milho mais concentrado (66SG), 34\% de silagem de girassol e $66 \%$ de silagem de milho mais concentrado (34SG), 100\% de silagem de milho mais concentrado (100SM) e $100 \%$ de silagem de milho mais caroço de algodão e concentrado $(16,5 \mathrm{CA})$.

As dietas foram balanceadas com valores constantes de proteína visando suprir os requisitos nutricionais dos animais (Tab. 1) de acordo com o Nutrient... (2001). Cinco dietas foram formuladas com farelo de soja, polpa cítrica, milho moído, farelo de algodão, calcário e fosfato bicálcico (Tab. 2). A relação volumoso:concentrado foi mantida constante, $56: 44 \%$, em relação à matéria seca $(\mathrm{MS})$ total da dieta. No tratamento $16,5 \mathrm{CA}$ a inclusão do caroço foi $16,5 \%$ da MS total, ou seja, substituiu $37,5 \%$ da porção de concentrado da dieta. 


\section{Silva et al.}

Tabela 1. Composição bromatológica das dietas segundo a proporção de silagem de girassol em substituição à silagem de milho e caroço de algodão em substituição parcial ao concentrado para vacas leiteiras

\begin{tabular}{lccccc}
\hline \multirow{2}{*}{ Composição bromatológica } & \multicolumn{5}{c}{ Dieta $^{*}$} \\
\cline { 2 - 6 } & $100 \mathrm{SG}^{1}$ & $66 \mathrm{SG}^{2}$ & $34 \mathrm{SG}^{3}$ & $100 \mathrm{SM}^{4}$ & $16,5 \mathrm{CA}^{5}$ \\
\hline MS, \% & 36,7 & 36,5 & 37,2 & 36,9 & 38,2 \\
PB, \%MS & 16,5 & 16,8 & 16,1 & 16,1 & 16,7 \\
FDN, \%MS & 42,8 & 44,1 & 45,6 & 47,7 & 47,8 \\
FDA, \%MS & 29,9 & 27,5 & 27,8 & 26,5 & 28,2 \\
EE, \%MS & 7,4 & 5,9 & 4,4 & 2,7 & 6,2 \\
\hline
\end{tabular}

* Dietas com proporções fixas de $44 \%$ de concentrado e $56 \%$ de volumoso na matéria seca. MS: matéria seca; PB: proteína bruta;

FDN: fibra em detergente neutro; FDA: fibra em detergente ácido; EE: extrato etéreo.

${ }^{1}$ Tratamento com silagem de girassol como volumoso único.

${ }^{2}$ Tratamento com $66 \%$ de silagem de girassol e $34 \%$ de silagem de milho como volumoso total.

${ }^{3}$ Tratamento com $34 \%$ de silagem de girassol e $66 \%$ de silagem de milho como volumoso total.

${ }^{4}$ Tratamento com silagem de milho como volumoso único.

${ }^{5}$ Tratamento com silagem de milho como volumoso único e caroço de algodão como substituto parcial, 37,5\%, do concentrado.

Tabela 2. Composição dos ingredientes e análise bromatológica dos concentrados utilizados em dietas contendo diferentes proporções de silagem de girassol em substituição à silagem de milho e caroço de algodão em substituição parcial ao concentrado para vacas leiteiras

\begin{tabular}{lccccc} 
& \multicolumn{3}{c}{ Concentrado* } \\
\cline { 2 - 6 } & $\mathrm{C} 1$ & $\mathrm{C} 2$ & $\mathrm{C} 3$ & $\mathrm{C} 4$ & $\mathrm{C} 5$ \\
\hline Ingrediente (\%) & & & & & \\
$\quad$ Farelo de soja & 28,0 & 30,5 & 33,0 & 35,5 & 22,1 \\
Farelo de algodão & 21,2 & 18,7 & 16,2 & 13,7 & 13,0 \\
Uréia & 1,2 & 1,2 & 1,2 & 1,2 & 1,2 \\
Milho grão moído & 8,9 & 8,9 & 11,4 & 16,4 & 2,6 \\
Polpa cítrica & 37,5 & 37,5 & 35,0 & 30,0 & 19,7 \\
Caroço de algodão & - & - & - & - & 37,5 \\
Bicarbonato de sódio & 1,3 & 1,3 & 1,3 & 1,3 & 1,3 \\
Mineral & 1,2 & 1,2 & 1,2 & 1,2 & 1,2 \\
Sal comum & 0,6 & 0,6 & 0,6 & 0,6 & 0,6 \\
Calcário calcítico & - & - & - & - & 0,6 \\
Composição bromatológica & & & & & 88,9 \\
MS, \% & 90,1 & 89,0 & 89,6 & 90,0 & 31,7 \\
PB, \%MS & 30,7 & 33,3 & 32,0 & 30,1 & 28,7 \\
FDN, \%MS & 20,8 & 19,2 & 22,2 & 18,4 & 21,5 \\
FDA, \%MS & 14,5 & 14,4 & 14,1 & 13,2 & 9,0 \\
EE, \%MS & 3,2 & 3,2 & 2,9 & 3,1 & \\
\hline
\end{tabular}

* C1: concentrado no tratamento com silagem de girassol como volumoso único da dieta; $\mathrm{C} 2$ : concentrado no tratamento com $66 \%$ de silagem de girassol e $34 \%$ de silagem de milho como volumoso total da dieta; C3: concentrado no tratamento com $34 \%$ de silgem de girassol e $66 \%$ de silagem de milho como volumoso total da dieta; $\mathrm{C} 4$ : concentrado no tratamento com silagem de milho como volumoso único da dieta; C5: concentrado no tratamento com silagem de milho como volumoso único e caroço de algodão como substituto parcial, $37,5 \%$, do concentrado da dieta.

MS: matéria seca; PB: proteína bruta; FDN: fibra em detergente neutro; FDA: fibra em detergente ácido; EE: extrato etéreo.

Os animais foram submetidos a duas ordenhas diárias, às 6 e 16 horas. As produções de leite foram calculadas utilizando-se os valores obtidos nas ordenhas consecutivas do $15^{\circ}$ ao $20^{\circ}$ dia de cada período experimental.

Para a avaliação da composição do leite, extrato seco total (EST), proteína bruta (PB), gordura, nitrogênio não protéico $(\mathrm{NNP})$, cinzas, $\mathrm{pH}$, acidez titulável e crioscopia foram coletadas amostras individuais, homogeneizadas, de $300 \mathrm{ml}$ de leite, em cada uma das quatro ordenhas consecutivas, do $17^{\circ}$ e $18^{\circ}$ dias de cada período experimental. As amostras, acondicionadas em recipiente contendo o conservante bronopol (2bromo 2-nitropropano 1,3-diol), na proporção de $10 \mathrm{mg}$ de princípio ativo para $50 \mathrm{ml}$ de leite, foram resfriadas a $4^{\circ} \mathrm{C}$. 
As análises de laboratório foram feitas no prazo máximo de sete dias após a coleta sendo cada ordenha analisada individualmente. Calculou-se a média ponderada de acordo com a produção por ordenha. Os resultados por período foram obtidos segundo a média aritmética dos resultados anteriormente citados nos dias de coleta.

O teor de extrato seco total foi determinado por secagem em estufa a vácuo segundo Association... (1997). O teor de gordura foi obtido pelo método de Mojonnier (Association..., 1997) utilizando-se frascos devidamente projetados. A proteína bruta foi obtida pelo método de Kjeldahl e o teor de cinzas obtido em mufla (Association..., 1997).

$\mathrm{O}$ teor de nitrogênio não protéico (NNP) foi determinado pelo método de Kjeldahl com precipitação protéica obtida pela adição de ácido tricloroacético (Association..., 1997). Foram ainda determinadas a acidez titulável em graus Dornic, o pH e o índice crioscópico.

Os dados de produção e composição do leite foram analisados pelo procedimento dos modelos fixos (Proc. GLM) do pacote estatístico SAS
(User's..., 1999). O teste Student-Newman-Keuls foi empregado para comparação entre tratamentos, sendo as diferenças consideradas significativas em $\mathrm{P} \leq 0,05$.

O modelo adotado foi:

$\mathrm{Y}_{\mathrm{ijk}}=\mu+\mathrm{A}_{\mathrm{i}}+\mathrm{P}_{\mathrm{j}}+\mathrm{T}_{\mathrm{k}}+\varepsilon_{\mathrm{ijk}}$, em que

$\mathrm{Y}_{\mathrm{ijk}}=$ resposta do animal $\mathrm{i}$, no período $\mathrm{j}$, sob o tratamento $\mathrm{k}$;

$\mu=$ média geral

$\mathrm{A}_{\mathrm{i}}=$ efeito do animal $\mathrm{i} ; \mathrm{i}=1,2,3,4,5$;

$\mathrm{P}_{\mathrm{j}}=$ efeito do período $\mathrm{j} ; \mathrm{j}=1,2,3,4,5$;

$\mathrm{T}_{\mathrm{k}}=$ efeito do tratamento $\mathrm{k} ; \mathrm{k}=1,2,3,4,5$;

$\varepsilon_{\mathrm{ijk}}=$ erro aleatório.

\section{RESULTADOS E DISCUSSÃO}

A produção de leite foi inferior $(\mathrm{P}=0,015)$ para o tratamento $100 \mathrm{SG}$ em relação aos tratamentos 66SG e 34SG ou ao tratamento 100SM (Tab. 3). Os tratamentos 66SG, 34SG e 100SM foram iguais entre si, demonstrando que a substituição parcial de silagem de milho por silagem de girassol não influenciou a produção de leite. A produção de LCG 4\% não foi influenciada pelos tratamentos.

Tabela 3. Produção e composição média do leite de vacas ingerindo diferentes quantidades de silagem de girassol em substituição à silagem de milho e caroço de algodão em substituição parcial ao concentrado

\begin{tabular}{|c|c|c|c|c|c|c|}
\hline \multirow{2}{*}{ - the } & \multicolumn{5}{|c|}{ Dieta* } & \multirow{2}{*}{ EPM } \\
\hline & $100 \mathrm{SG}^{1}$ & $66 \mathrm{SG}^{2}$ & $34 \mathrm{SG}^{3}$ & $100 \mathrm{SM}^{4}$ & $\mathrm{CA}^{5}$ & \\
\hline \multicolumn{7}{|l|}{$\mathrm{kg} / \mathrm{dia}$} \\
\hline Leite & $24,0 \mathrm{~b}$ & $27,2 \mathrm{a}$ & $27,5 \mathrm{a}$ & $27,4 \mathrm{a}$ & $25,5 \mathrm{ab}$ & 0,702 \\
\hline LCG $4 \%$ & 22,6 & 25,2 & 25,0 & 26,2 & 25,5 & 0,867 \\
\hline Gordura & 0,867 & 0,956 & 0,935 & 1,016 & 1,019 & 0,116 \\
\hline Proteína & $0,700 \mathrm{~b}$ & $0,744 a b$ & $0,778 \mathrm{ab}$ & $0,836 \mathrm{a}$ & $0,770 \mathrm{ab}$ & 0,060 \\
\hline EST & $2,586 \mathrm{~b}$ & $2,930 \mathrm{a}$ & $2,969 a$ & $3,039 a$ & $2,943 \mathrm{a}$ & 0,174 \\
\hline \multicolumn{7}{|l|}{$\mathrm{g} / 100 \mathrm{~g}$} \\
\hline Gordura & 3,63ab & $3,52 \mathrm{ab}$ & $3,39 b$ & $3,69 \mathrm{ab}$ & $3,99 a$ & 0,042 \\
\hline Proteína & $2,91 \mathrm{ab}$ & $2,72 b$ & $2,83 \mathrm{ab}$ & $3,04 \mathrm{a}$ & $3,01 \mathrm{a}$ & 0,026 \\
\hline Cinzas & 0,876 & 0,752 & 0,749 & 0,867 & 0,799 & 0,034 \\
\hline EST & 10,76 & 10,78 & 10,84 & 11,06 & 11,52 & 0,079 \\
\hline \multicolumn{7}{|l|}{$\mathrm{mg} / 100 \mathrm{~g}$} \\
\hline NNP & 37,18 & 37,65 & 36,59 & 35,99 & 35,48 & 0,001 \\
\hline
\end{tabular}

Valores com diferentes letras na mesma linha diferem entre si $(\mathrm{P} \leq 0,05)$.

* Dietas com proporções fixas de $44 \%$ de concentrado e $56 \%$ de volumoso na matéria seca.

${ }^{1}$ Tratamento com silagem de girassol como volumoso único.

${ }^{2}$ Tratamento com $66 \%$ de silagem de girassol e $34 \%$ de silagem de milho como volumoso total.

${ }^{3}$ Tratamento com $34 \%$ de silagem de girassol e $66 \%$ de silagem de milho como volumoso total.

${ }^{4}$ Tratamento com silagem de milho como volumoso único.

${ }^{5}$ Tratamento com silagem de milho como volumoso único e caroço de algodão como substituto parcial, 37,5\%, do concentrado.

EPM: erro padrão da média; LCG4\%: leite corrigido para 4\% de gordura; EST: extrato seco total; NNP: nitrogênio não protéico. 


\section{Silva et al.}

Estes resultados são semelhantes aos de McGuffey e Schingoethe (1980), que compararam a produção de vacas alimentadas exclusivamente com silagem de girassol ou silagem de milho e encontraram produções inferiores para as alimentadas com silagem de girassol. Nesse trabalho os valores de LCG 4\% foram semelhantes.

Não houve diferença na produção de leite entre $16,5 \mathrm{CA}$ e $100 \mathrm{SM}$ e entre $16,5 \mathrm{CA}$ e todos os tratamentos que incluíram silagem de girassol. Anderson et al. (1980) e Vilela et al. (1996) não observaram efeito da inclusão de até $30 \%$ de caroço de algodão sobre a produção de leite corrigido ou não para $4 \%$ de gordura. Anderson et al. (1979) encontraram valores superiores de produção de leite e LCG 4\% para vacas alimentadas com caroço de algodão e Smith et al. (1981) também relataram valores superiores para LCG4\%.

A concentração de gordura do leite foi semelhante entre os tratamentos 100SG, 66SG, $34 \mathrm{SG}$ e 100SM. A produção de gordura acompanhou a tendência observada para a produção de leite e a produção de LCG4\%. Esse fato demonstra que não houve inibição da síntese de gordura em nenhum dos tratamentos. Essa inibição seria esperada principalmente em razão do maior conteúdo de lipídeos insaturados em dietas com silagem de girassol e, ainda, devido aos efeitos ruminais e pós-ruminais desses ácidos graxos. Efeito ruminal dos lipídios que acarretam diminuição dos teores de gordura do leite geralmente está associado a efeito tóxico sobre a população bacteriana, resultando em diminuição da produção de acetato e butirato no rúmen, substratos fundamentais para a síntese de gordura na glândula mamária (Banks et al., 1983). A ação específica de alguns ácidos graxos de cadeia longa reduzindo a síntese de novo de ácidos graxos na glândula mamária seria um mecanismo pós-ruminal da ação dos lipídios sobre a produção de gordura (Banks et al., 1984). Segundo MacLeod et al. (1976), quantidade moderada de lipídios insaturados na dieta causa diminuição da concentração da gordura do leite, algumas vezes superior a uma unidade percentual. O óleo contido tanto na silagem de girassol como no caroço de algodão está, de certa forma, protegido fisicamente por se apresentar no interior das sementes. Esse fato, associado à sua lenta e constante liberação para o interior do rúmen, pode explicar a ausência de efeito inibitório sobre a produção de gordura pelos animais.

Efeito da silagem de girassol sobre os teores de gordura do leite são controversos. McGuffey e Schingoethe (1980) observaram maior teor de gordura no leite de vacas alimentadas com silagem de girassol em comparação às alimentadas com silagem de milho, enquanto Valdez et al. (1988) observaram menor percentagem de gordura do leite em vacas alimentadas exclusivamente com silagem de girassol.

Os resultados de porcentagem de gordura nos tratamentos 100SM e 16,5CA assemelham-se parcialmente aos de Coppock et al. (1987). Segundo os autores, a inclusão de 100 a $300 \mathrm{~g} / \mathrm{kg}$ de MS de caroço de algodão a dietas aumentou o conteúdo de gordura do leite em oito dentre 13 experimentos realizados, mas somente em quatro a diferença foi significativa em relação à dietacontrole.

A percentagem de proteína do leite variou de 2,7 a $3,0 \%$. A percentagem de proteína do leite no tratamento $66 \mathrm{SG}$ foi menor $(\mathrm{P}=0,015)$ do que a dos tratamentos 100SM e 16,5CA, mostrando que a inclusão parcial de silagem de girassol em $66 \%$ do volumoso total influenciou negativamente o teor de proteína do leite. Esse fato pode estar parcialmente relacionado aos efeitos da maior concentração de lipídeos na dieta. Segundo Emery (1978), os lipídeos diminuem em 0,1 a 0,3 unidades percentuais o teor de proteína do leite. Não houve variação no teor de proteína do leite entre os tratamentos com maior teor de lipídio na dieta (100SG e 16,5CA) e o tratamento com menor teor de lipídio (100SM).

A produção de proteína não foi afetada pela substituição parcial da silagem de milho pela de girassol, pois os tratamentos 66SG, 34SG e 100SM foram semelhantes entre si, 0,744, 0,778 e $0,836 \mathrm{~kg} / \mathrm{dia}$, respectivamente. A produção de proteína foi inferior $(\mathrm{P}=0,036)$ no tratamento $100 \mathrm{SG}(0,700 \mathrm{~kg} / \mathrm{dia})$ em relação ao $100 \mathrm{SM}$ $(0,836 \mathrm{~kg} / \mathrm{dia})$, acompanhando a tendência também observada para a produção de leite. Não houve diferença entre o tratamento $16,5 \mathrm{CA}$ e $100 \mathrm{SM}$, mostrando que a inclusão de $16,5 \%$ de caroço de algodão na MS da dieta não interferiu 
na produção e porcentagem de proteína do leite. Vários estudos demonstraram não haver interferência da suplementação de caroço de algodão na produção e concentração de proteína do leite (Smith e Vosloo, 1994; Wu et al., 1994; Belibasakis e Tsirgogianni, 1995). Coppock et al. (1987) revisaram 18 experimentos publicados entre 1978 e 1985 e relataram que a metade dos experimentos demonstraram queda do teor de proteína do leite com a inclusão do caroço de algodão. Devido ao pequeno aumento na produção de leite, poucos foram os relatos de queda da produção total de proteína.

A percentagem de EST do leite não foi influenciada pelos tratamentos. A produção total de EST seguiu a mesma tendência observada na produção de leite e proteína. Foi significativamente inferior em 100SG $(\mathrm{P}=0,013)$ quando comparado aos outros tratamentos. A inclusão de caroço de algodão à dieta não influenciou a percentagem ou a produção total de EST do leite.

Os teores médios de NNP do leite variaram de 35,48 a $37,65 \mathrm{mg} / 100 \mathrm{~g}$ e não houve diferença estatística entre os tratamentos. Essa constância nos valores encontrados reflete a constância do metabolismo de $\mathrm{N}$ dos animais, pois segundo DePeters e Cant (1992), a maioria dos compostos que constituem o NNP do leite são produtos finais desse metabolismo. Apesar das dietas terem sido isoprotéicas, outros fatores como degradabilidade das proteínas, quantidade ingerida ou mesmo diferentes fontes de suprimento de energia (carboidratos ou lipídios) nas dietas poderiam ter influenciado o teor de NNP do leite, o que não ocorreu.

A porcentagem de cinzas não foi influenciada pelos tratamentos, ficando entre 0,749 e $0,876 \%$. Estes resultados estão de acordo com os de Rosenthal (1991) que menciona ser a porcentagem média de cinzas do leite constante e próxima a $0,7 \%$.

\section{CONCLUSÕES}

A inclusão parcial da silagem de girassol na dieta de vacas leiteiras em substituição à silagem de milho é viável no nível de produção relatado neste experimento, aproximadamente $26 \mathrm{~kg}$ leite, por não alterar as produções de leite, de LCG4\%, de proteína e de gordura. A substituição completa da silagem de milho pela silagem de girassol não deve ser recomendada em razão de reduções nas produções de leite, proteína e EST.

\section{REFERÊNCIAS BIBLIOGRÁFICAS}

ANDERSON, M.J.; ADAMS, D.C.; LAMB, R.C. et al. Feeding whole cottonseed to lactating dairy cows. J. Dairy Sci., v.62, p.1098-1103, 1979.

ANDERSON, M.J.; LAMB, R.C.; WALTERS, J.L. Comparison of four levels of whole cottonseed for lactating dairy cows. J. Dairy Sci., v.63 (suppl. 1), p.38 e 39, 1980.

ARIELI, A. Whole cottonseed in dairy cattle feeding: a review. Anim. Feed Sci. Techn., v.72, p.97-110, 1998.

ASSOCIATION of Official Analytical Chemists. Official methods of analysis. 16.ed. Gaithersburg: AOAC, 1997.

ASTRUP, M.N.; VIK-MO, L.; EKERN, A. et al. Feeding protected and unprotected oils to dairy cows. J. Dairy Sci., v.59, p.426-430, 1976.

BANKS, W.; CLAPPERTON, J.L.; GIRDLER, K. et al. Effect of inclusion of different forms of dietary fatty acid on the yield and composition of cow's milk. J. Dairy Res., v.51, p.387-395, 1984.

BANKS, W.; CLAPPERTON, J.L.; STEELE, W. Dietary manipulation of the content and fatty acid composition of milk fat. Proc. Nutr. Soc., v.42, p.399-406, 1983.

BELIBASAKIS, N.G.; TSIGOGIANNI, D. Effect of whole cottonseed on milk yield, milk composition, and blood components of dairy cows in got weather. Anim. Feed Sci. Technol., v.52, p.227-235, 1995.

CHANDLER, P. Whole cottonseed has economic feeding value for dairy cattle. Feedstuffs, v.64, p.10-11, 1992.

COPPOCK, C.E.; LANHAM, J.K.; HORNER, J.I. A review of the nutritive value and utilization of whole cottonseed, cottonseed meal and associated by-products by dairy cattle. Anim. Feed Sci. Technol., v.18, p.89-129, 1987.

DePETERS, E.J.; CANT, J.P. Nutritional factors influencing the nitrogen composition of bovine 
milk: a review. J. Dairy Sci., v.75, p.2043-2070, 1992.

DePETERS, E.J.; TAYLOR, S.J.; FRANKE, A.A. et al. Effects of feeding whole cottonseed on composition of milk. J. Dairy Sci., v.68, p.897-902, 1985.

EMERY, R.S. feeding for increase milk protein. J. Dairy Sci., v.61, p.825-828, 1978.

KELLY, M.L. Dietary fatty acid sources affect conjugated linoleic acid concentrations in milk from lactating dairy cows. J. Nutr. v.128, p.881885,1998 .

MacLEOD, G.; YU. Y.; SCHAEFFER, L.R. Feeding value of protected animal tallow for high yielding dairy cows. J. Dairy Sci., v.60, p.726-738, 1976.

McGUFFEY， R.K.; SCHINGOETHE， D.J. Feeding value of high oil variety of sunflowers as silage to lactating dairy cows. J. Dairy Sci., v.63, p.1109-1113, 1980.

NUTRIENT requirements of dairy cattle. Washington D.C.: NRC, 2001.

PENNINGTON, J.A.; DAVIS, C.L. Effects of intraruminal and intra-abomasal additions of cod-liver oil on milk fat production in the cow. $J$. Dairy Sci., v.58, p.49-55, 1975.

ROSENTHAL, I. Milk and dairy products: Properties and Processing. 1. ed. Rehovot: Balaban Publishers, 1991. 217p.

SMITH, N.E.; COLLAR, L.S.; BATH, D.L. et al. Digestibility and effects of whole cottonseed fed to lactating cows. J. Dairy Sci., v.64, p.2209$2215,1981$.

SMITH, W.A.; VOSLOO, L.P. Effect of whole cottonseed, heat-treated whole cottonseed and whole cottonseed plus lanolin on milk production and composition. S. Afr. J. Anim. Sci., v.24, p.4548, 1994.

STEELE, W.; MOORE, J.H. The effects of dietary tallow and cottonseed oil on milk yield and composition in the cow. J.Dairy Res., v.35, p.223-229, 1968

THOMAS, V.M.; GLENN, A. MURRAY; THACKER, D.L. et al. Sunflower silage in rations for lactating holstein cows. J. Dairy Sci., v.65, p.267-270, 1982.

TOMICH, T.R.; RODRIGUES, J.A.S.; GONÇALVES, L.C. et al. Potencial forrageiro de cultivares de girasol produzidos na safrinha para ensilagem. Arq. Bras. Med. Vet. Zootec., v.55, p.756-762, 2003.

USER'S guide: statistics. Cary, NC: SAS Institute, 1999.

VALDEZ, F.R.; HARRISON, J.H.; FRASEN, S.C. Effect of feeding sunflower silage on milk production, milk composition, and rumen fermentation of lactating dairy cows. J. Dairy Sci., v.71, p.2462-2469, 1988

VILLELA, S.D.J.; VALADARES FILHO, S.C.V.; SILVA, J.F.C. et al. Caroço de algodão para vacas leiteiras (consumo de nutrientes, produção e composição do leite). Rev. Soc. Bras. Zoot., v.25, p.298-308, 1996.

WU, Z.; HUBER, J.T.; CHAN, S.C. et al. Effect of source and amount of supplemental fat on lactation and digestion in cows. J. Dairy Sci., v.77, p.1644-1651, 1994.

YANG, Y.T.; ROHDE, J.M.; BALDWIN, R.L. Dietary lipid metabolism in lactating dairy cows. J. Dairy Sci., v.61, p.1400-1406, 1978. 